\title{
LAS SECUENCIAS DEL GRUPO INDEPENDENCIA (PERMICO) AFLORANTES EN COLONIA INDEPENDENCIA Y AL OESTE DE CAAGUAZŨ, PARAGUAY ORIENTAL: LITOFACIES, PALEOCORRIENTES E INTERPRETACIÓN PALEOAMBIENTAL
}

Renato R. Andreis (CONICET/NESE, UNISINOS)

Lorenzo A. Ferrando (Fac. de Agronomia, Montevideo)

Gullermo A. Jalfin (CONICET/Depto. Ciências Geológicas, Buenos Aires)

Sobre la base de perfiles estratigráficos detallados efectuados en los alrededores de Colonia Independencia (Melgarejo, Ao Vino y Pañetey, Fig. 1, 2AD) y en la Ruta Nacional № 2 al Deste de Caaguazú (A으 Morotí, Km 161 y Calera Cachimbo, Km 165) son analizadas las secuencias siliciclásticas de las Formaciones San Miguel, Tacuary y Tapytá. Estas unidades integran el Grupo Independencia (sensu Jalfin, 1986), cuyo espesor alcanza a $600 \mathrm{~m}$ (en subsuelo). En la región su base no es visible, pero más al Norte, en las inmediaciones de Mbutuy, las secuencias se apoyan concordantes en las sedimentitas de la F. Coronel oviedo asignadas al lapso Carbonífero tardío-Pérmico temprano (Herbst y Leguizamón, 1984; Clerici et al., 1986). Asimismo, fueron examinadas las eolianitas post-Tapytá, aflorantes en Ao Pañetey (F'ig. 2D) y Cantera Boca (Fig. 1). Las sucesiones estudiadas se ubican en el borde occidental de la Cuenca Paraná, al Este del Arco de Asunción.

La primera unidad presenta tonalidades amarillentas y castañas dominantes, asociadas con tonos verdosos, blanquecinos y grises. La estratificación es tabular centimétrica a decimétrica con contactos planos definidos. Comprende facies arenosas (57\%), heterolíticas (29\%) y pelíticas (15\%). La primera incluye psamitas finấ y medias con cemento carbonático, macizas por bioturbación (Sm), laminadas - en capas tabulares delgadas (Sh) o con escasas óndulas de corriente (Sr, con bioturbaciones de tipo epichnia) que indican paleocorrientes hacia el NO. La facies heterolítica está representada por interlaminaciones de psamitas finas ( 0 li molitas arenosas) y arcilitas, y estructuras flaser y ondulosa, mientras que la pelítica comprende limolitas y arcilitas macizas o laminadas y muy micáceas. Las secuencias contienen restos fósiles vegetales (licopsidas, pteridófitas, gimnospermas, carófitas, megaesporas) y pelecípodos, crustáceos y ostrácodos dulce acuí colas (Herbst, 1972, 1981 a,b,c,; Zabert, 1985).

En transición continúa la F. Tacuary caracterizada por la aparición de colores rijizos y púrpura (entre los tonos típicos para la unidad anterior) y de al gunos cambios sustanciales en su estratificación, frecuencias litofaciales y contenido paleobiológico. Además del discreto aumento en el espesor medio de los estratos, se advierte la aparición de geometrías canalizadas con contactos ondulacios o irregulares (de génesis erosiva) y de litofacies calcáreas (5\%) asociadas a las 


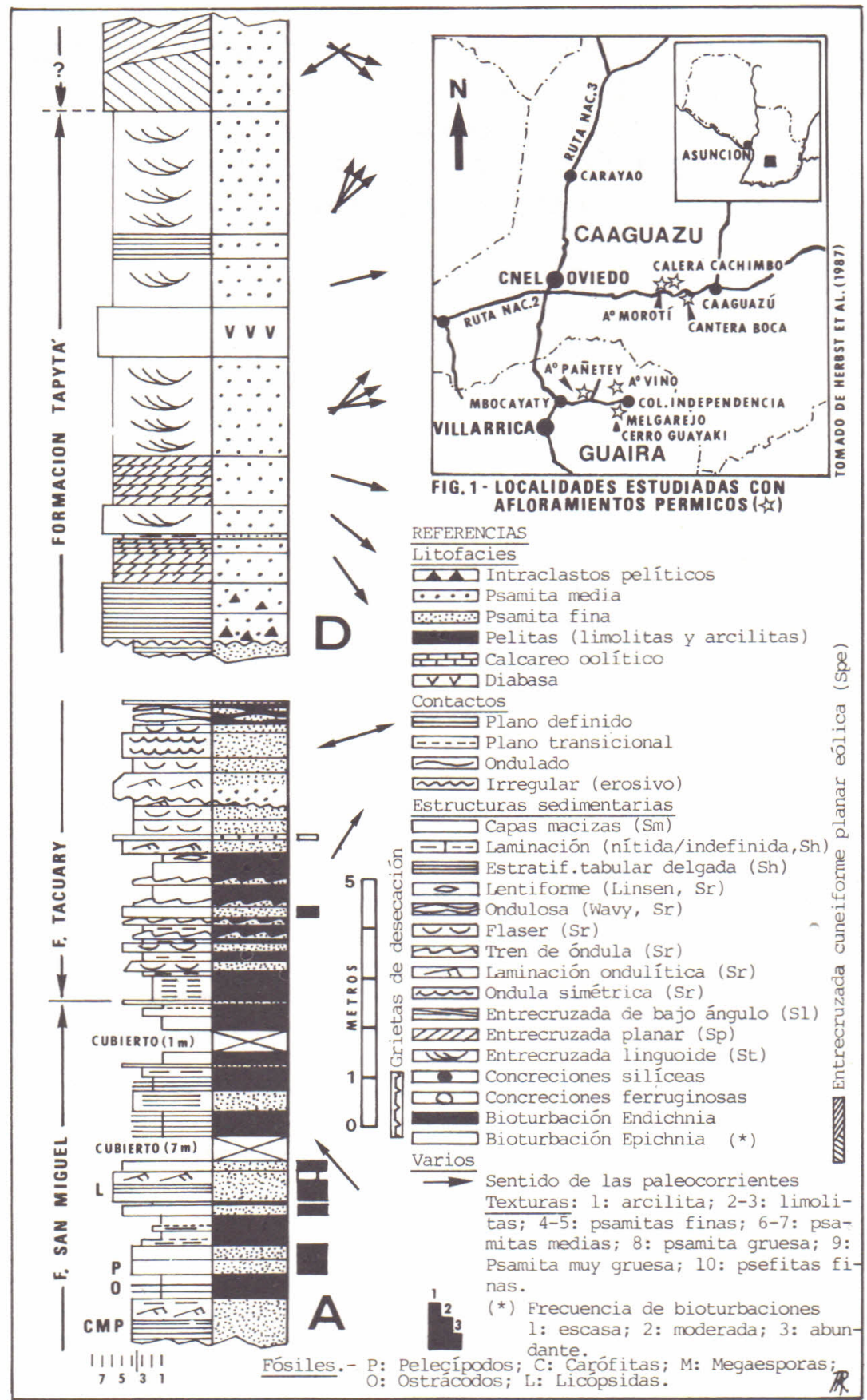


arenosas (4l\%), heterolíticas (32\%) y pelíticas (22\%). En las litofacies arenosas y heterolíticas aumenta la participación de estructuras generadas por la migración de óndulas (Sr): laminación ondulítica ascendente (tipos A y B), trenes de óndulas de corriente u oleaje y estructuras flaser, ondulosa y lentiforme, en detrimento de las facies Sm y Sh, y aparecen grietas de desecación y de sinéresis. Son frecuentes las bioturbaciones (endichnia y epichnia). Los calcáreos están representados por cuerpos tabulares (a nivel de afloramiento) de osparitas y omicritas grises macizas (capas delgadas) o con estratificaciōn entrecruzada de bajo ángulo (Sl) o tangenciales (Sp, porte 7-15 cm) en los cuerpos métricos (Fig. 2B); ocasionalmente, hay óndulas de corriente e intraclastos pelíticos, así como moldes de pelecípodos de agua dulce o delgadas coquinas con conchillas fragmentadas y sin orientación (Herbst et al., 1987). Los calcáreos están parcialmente sustituidos por nódulos silíceos dispuestos en horizontes.

El análisis de la orientación de las estructuras direccionales permite com probar la actividad de mareas, en especial en la facies calcárea (Dig. 2B). Se han reconocido agrupamientos preferenciales, cuyos valores promedio indican paleo corrientes hacial el NNO, SSE y SO y, menos definidas, al ENE (Fig. 3A).

Aparentemente en concordancia siguen las secuencias arenosas rojizas de la F. Tapytá. Constituída por psamitas medias y escasas finas, feldespáticas y micáceas, y algunas pelitas e intraclastos pelíticos, presenta estratificación lenticular media a gruesa (máximo 2,50 m); las estructuras entrecruzadas planares y en artesa (Sp y St) predominan sobre la estratificación tabular delgada (Sh). Las pa leocorrientes muestran amplia distribución con valor promedio orientado al NE(51으 Fig. 3B). Las psamitas contienen troncos silicificados de helechos arborescentes de gran porte (Herbst, 1981a).

También en concordancia se sobreponen las eolianitas post-Tapytá formadas por facies arenosas medias con tonalidades rojizo-anaranjadas y estructuras entre cruzadas cuneiformes planares (Spe); éstas muestran gran distribución y orientación promedio hacia el S (177, fig. 3C).

Definida como una secuencia grano y estratocreciente poco definida con caractêrísticas regresivas (Jalfin, 1986), las sedimentitas del Grupo Independencia habrían comenzado a depositarse en el Pérmico inferior más alto durante la expansión de los mares del Artinskiano al Kunguriano y culminado en el Pérmico superior tardío con la definitiva continentalización de la región (Jalfin, 1986). Los procesos regresivos se deberían a fenómenos eustáticos débiles ocurridos hacia el final de la sedimentación Iratí en el Brasil (Petri y Fúlfaro, 1983; Cazzulo-Klep zig et al., 1988). Las secuencias pérmica paraguayas, por sus características litofaciales, cromáticas y paleontológicas (en especial, la asociación de pelecípodos pertenecientes a la fauna de Pinzonella neotrópica) se correlacionan con las formaciones del intérvalo Iratí (parte superior)-Serra Alta-Teresina-Rio do Rasto - Corumbataí en Brasil y Melo-Yaguari en Uruguay.

La sucesión local habría iniciado su evolución con la generación de lagos de agua dulce o salobre (San Miguel), a veces conectados con el mar, establecidos en sectores periféricos de amplias bahías someras durante el lento pero persisten te retroceso del mar. Allí se desarrollaron faunas de pelecípods y ostrácodos en 


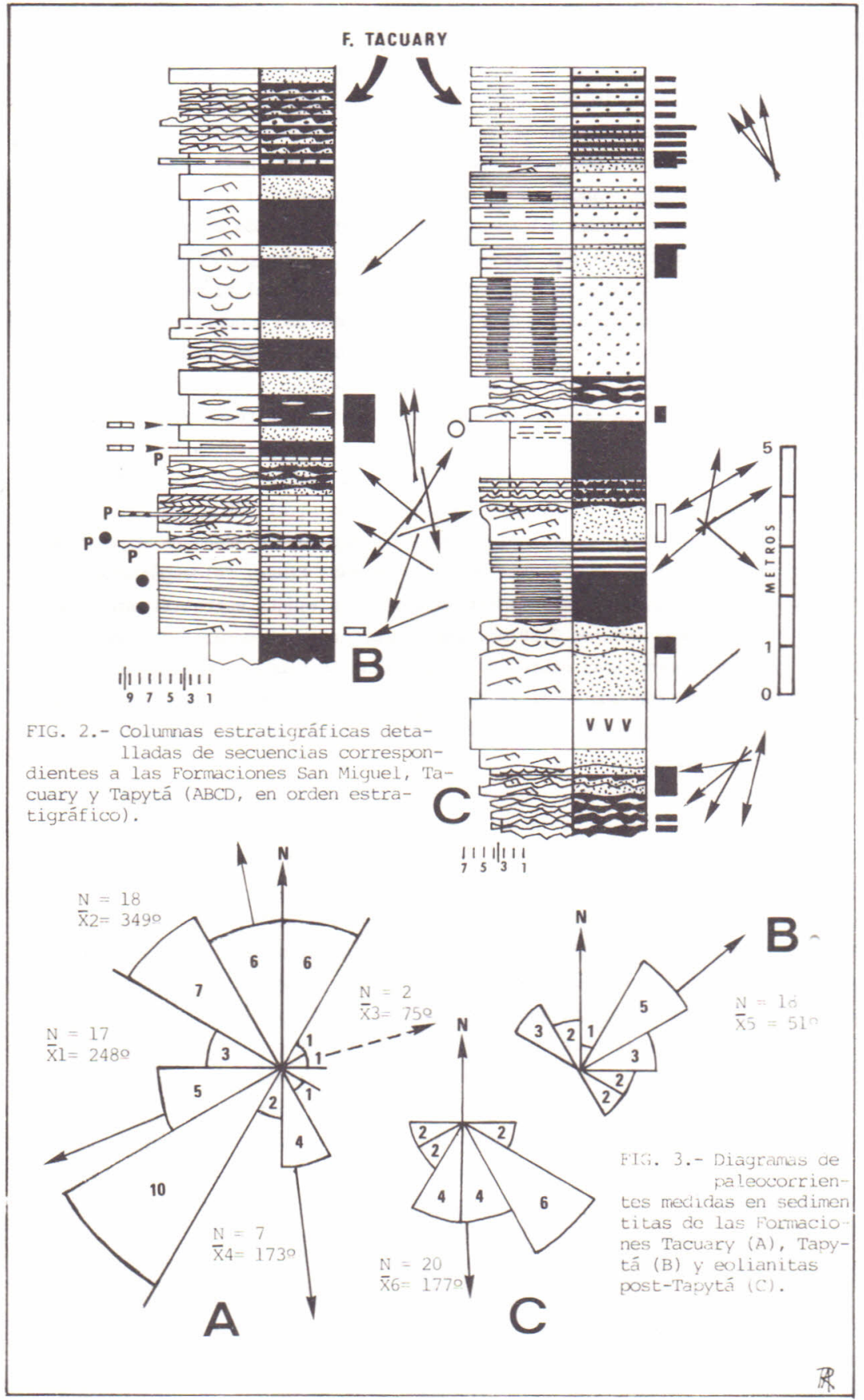


condiciones de extrema aislación y con evolución endémica (Zabert, 1985).

Las secuencias de la F. Tacuary parecen representar condiciones aún mấs so meras con la instalación de un sistema albúfera-planicie mareal, con barras y canales mareales y barras offshore, bajo condiciones micro a mesomareales y de mayor oxidación; no faltan facies de tempestitas. La evolución continúa con la continentalización definitiva de la región con la progradación de clásticos más grue sos a través de sistemas fluviales entrelazados (Jalfin, 1986). La vegetación arbórea se habría desarrollado bordeando los canales fluviales (Herbst, com.pers.) A semejanza de la evolución en otros sectores de la Cuenca Paraná, la progresiva aridización se manifiesta con la instalación de campos de dunas y cambios en las comunidades paleoflorísticas.en el pasaje del Pérmico al Triásico. Por sus paleocorrientes al S, las eolianitas post-Tapytá pueden ser paralelizadas con aquellas correspondientes a la F.Cuchilla Ombú en Uruguay (Ferrando y Andreis, 1986).

\section{BIBLIOGRAFIA}

CAZZULO-KLEPZIG, M.; PICCOLI, A.E.M. Y MARQUES-TOIGO, M., 1988. Palaeoecology of the Guatá and Passa Dois Groups. Permian of the Paraná Basin, southern Brazil VII Gondwana Symp., Sao Paulo. Abstracts, p.60.

CLERICI, A.M.V.C.; SUGUIO, K. Y FULFARO, V.J., 1986. Reavaliação da geología do Paraguai Oriental. Congresso Brasileiro de Geología, 34, Goiania, 1986.Anais 1: $163-176$.

FERRANDO, L.A. Y ANDREIS, R.R., 1986. Nueva estratigrafía en el Gondwana de Uruguay. I Congreso Latinoamericano de Hidrocarburos, Buenos Aires, Argentina, 1986. 1; 295-323.

HERBST, R., 1972. Nota sobre la presencia de Lycopsidae arborescentes en el Pérmi co (Serie Independencia) del Paraguay. Ameghiniana, 9 (3): 258-264, Buenos Aires.

HERBST, R., 1981a. Guairea Milleri nov. gen. et sp. y Guaireacea, nueva Familía de las Osmundales (sensu lato) del Pérmico superior de Paraguay. Ameghiniana, $18(1-2): 35-50$, Buenos Aires.

HERBST, R., 1981b. Sobre la presencia de girogonites de Leonardosia langei Sormer (Charales, Porocharacea) en el Pérmico superior de Paraguay y Brasil. II Congresso Latinoamericano de Paleontología, Porto Alegre. Anais, 1: 249-255.

HERBST, R., 1981c. Impresiones de megaesporas y otros restos plantíferos del Pérmico superior de Paraguay. Facena (Corrientes, Argentina), 4: 31-43.

HERBST, R. y LEGUIZAMON, R., 1984. La Formación Independencia (Pérmico superior) del Paraguay: caracteres litológicos y paleontológicos. Facena (Corrientes, Argentina), 5: 71-87.

HERBST, R., 1986. Cyclodendron cf. leslii Sew. (Licopodosidaceae, Lycopsidae) del Pérmico de Paraguay y Uruguay. Facena (Corrientes, Argentina), 6: 33-43.

HERBST, R.; MORTON, L.S. y FERRANDO, L.A., 1987. Los pelecípodos dulceacuícolas del Pérmico superior de Paraguay y Uruguay. Rev.Asoc. Ciencias Naturales del Litoral, 18 (2): 107-122.

JALFIN, G. A., 1986. Evolución paleoambiental del Grupo Independencia, Pérmico del Paraguay Oriental. Annual Meeting Working Group, Project 211 IUGS, Córdo ba (Argentina), 79-80.

PETRI, S. y FULFARO, V.J., 1983. Geología do Brasil. Edit.Univ.Sāo Paulo, 631 p.

ZABERT, L.L., 1985. Ostrácodos de agua dulce del Pérmico superior de Colonia Independencia (Dpto. Guairá), Paraguay. Ameghiniana, 22 (1-2): 121-131. 
